\title{
Expression of regulator of G-protein signalling protein 2 (RGS2) in the mouse uterus at implantation sites
}

\author{
Z-P. Huang ${ }^{1}$, H. Ni ${ }^{2}$, Z-M. Yang ${ }^{2}$, J. Wang ${ }^{1 *}$, J-K. Tso ${ }^{1}$ and Q-X. Shen ${ }^{1}$ \\ ${ }^{1}$ Shanghai Institute of Planned Parenthood Research, Shanghai 200032, China; and ${ }^{2}$ College of Life \\ Science, Northeast Agriculture University, Harbin 150030, China
}

\begin{abstract}
Establishment of an active dialogue between the maternal endometrium and the implanting blastocyst is essential for successful implantation. The aim of this study was to identify genes that are explicitly expressed at implantation sites of the mouse uterus by subtractive hybridization. One expressed sequence tag of the genes identified showed $92 \%$ identity to the regulator of G-protein signalling protein 2 (RGS2). The full cDNA sequence of this gene was amplified by PCR and subsequently registered in GenBank. The sequence of its open reading frame encoding 211 amino acids
\end{abstract}

was the same as that of mouse RGS2, with the exception of four amino acids. Northern blot analysis showed that the expression of this gene was much higher at implantation sites than at inter-implantation sites on days 5-8 of pregnancy. In situ hybridization localized this mRNA predominantly to the stromal cells at the implantation sites. These results indicate that RGS2 has a role during implantation, possibly by regulating the intracellular $\mathrm{Ca}^{2+}$ mobilization and T-cell proliferation at the maternal-fetal interface.

\section{Introduction}

Synchronized development of an embryo to the blastocyst stage and differentiation of the uterus to the receptive state are essential for implantation (Psychoyos, 1973; Paria et al., 1993). Embryo implantation involves intricate co-ordination of endometrial and blastocyst factors for the correct attachment of the embryo and its subsequent controlled invasion into maternal decidua. Numerous factors, including growth factors, cytokines, homeotic genes and other molecules, are implicated in the embryo implantation process (Nie et al., 1997; Rinkenberger et al., 1997; Carson et al., 2000; Reese et al., 2001). However, the molecular mechanism of this process is still not clearly understood.

In the present study, CLONTECH PCR-select cDNA subtraction technique was used to search for the novel molecules that are highly expressed at the implantation sites compared with the inter-implantation sites in the mouse, with a view to identifying unrecognized factors involved in implantation. CLONTECH PCR-select cDNA subtraction is a unique method based on selective amplification of differentially expressed sequences, which overcomes the technical limitations of traditional subtraction methods (Diatchenko et al., 1998).

A number of clones were obtained from the subtracted cDNA library. One of these clones contained a cDNA fragment that was similar to the regulator of G-protein signalling protein-2 (RGS2). The expression pattern and

*Correspondence

Email: kjb@sippr.stc.sh.cn cellular distribution of RGS2 during embryo implantation have not been examined. The aim of the present study was to obtain the full-length cDNA sequence of this RGS2-like gene and examine its expression pattern in the uterus during early pregnancy and in other non-uterine tissues.

\section{Materials and Methods}

\section{Animals and treatments}

Adult ICR mice aged 6-7 weeks (female 25-30 g, male 35-40 g) were obtained from the SIPPR-BK Lab Animal Ltd Co. (Shanghai). All of the mice were maintained under a controlled temperature (approximately $22^{\circ} \mathrm{C}$ ) under a $14 \mathrm{~h}$ light:10 h dark photoperiod. Adult female mice were mated with fertile or vasectomized males of the same strain to achieve pregnancy or pseudopregnancy, respectively.

All experimentation was in full compliance with the standard laboratory animal care protocols approved by the Institutional Animal Care Committee of Shanghai Institute of Planned Parenthood Research. Adult female mice were mated with fertile males of the same strain (day $1=$ day of appearance of a vaginal plug). Pregnancy was confirmed on days 1-4 by recovering embryos from the reproductive tracts. The implantation sites on days 5-6 were identified by i.v. injection of Chicago blue dye solution ( $1 \%$ in saline, $0.1 \mathrm{ml}$ per mouse).

The whole uterus was collected from non-pregnant mice and from pregnant mice from day 1 to day 4 of pregnancy. For days 5-9 of pregnancy, implantation sites (plus embryos) and inter-implantation sites were 
collected separately from three mice on each day. Embryos were removed from the implantation sites of day 7 , day 8 and day 9 pregnant mice. Embryos were also collected by flushing the uterus with PBS at 07:00-08:00 $\mathrm{h}$ on day 5 of pregnancy.

Pseudopregnant mice were obtained by mating the females with vasectomized males. Sesame oil ( $50 \mu \mathrm{l}$ ) was intraluminally infused into the uterine horn on day 4 of pseudopregnancy to induce decidualization. The uterus under induced decidualizaton was collected on day 8 of pseudopregnancy. Delayed implantation was induced by ovariectomizing pregnant mice at 08:30-09:00 $\mathrm{h}$ on day 4 of pregnancy. Progesterone (1 mg per mouse) was injected to maintain delayed implantation from day 5 to day 7. Oestradiol (100 ng per mouse) was administered to progesterone-primed delayed-implantation mice to terminate delayed implantation. The implantation sites were identified by i.v. injection of Chicago blue solution. The mice were killed by cervical dislocation and their uteri were collected at $24 \mathrm{~h}$ after oestrogen treatment. Delayed implantation was confirmed by flushing the blastocysts from the uterus.

Ovary, heart, spleen, kidney, liver, muscle and brain were collected from one day 5 pregnant female ICR mouse. Testis and epididymis were collected from one adult male ICR mouse. All of the tissues collected were stored at $-80^{\circ} \mathrm{C}$ until further analysis.

\section{PCR-select cDNA subtractive hybridization}

Total RNA was extracted from the pools of implantation sites (plus embryos), the pools of inter-implantation sites and the pools of embryos of day 5 pregnant mice using TRIZOL solution (Gibco-BRL). The PolyATtract mRNA preparation kit (Promega, Madison, WI) was used to purify mRNA from the total RNA. The amount of mRNA was determined using a spectrophotometer, and the quality of RNA was evaluated by the ratio of $\mathrm{OD}_{260}: \mathrm{OD}_{280} \quad(>1.8)$. A CLONTECH PCR-select ${ }^{\mathrm{TM}}$ cDNA subtraction kit (CLONTECH Laboratories Inc.) was used to construct the subtracted cDNA library according to the user manual of the kit (PT1117-1). Specifically, the synthesized cDNA derived from day 5 implantation sites (plus embryos) was referred to as 'tester'. The synthesized cDNA derived from day $5 \mathrm{em}-$ bryos was added to an equal amount of the synthesized cDNA derived from the day 5 implantation sites. This mixed pool of synthesized cDNA was then referred to as 'driver' to remove the embryo-originated cDNA contained in the 'tester'.

\section{cDNA cloning and sequence analysis}

Two microlitres of subtracted cDNA products were taken from the $25 \mu \mathrm{l}$ secondary PCR mixture and used for cDNA subcloning. These cDNA fragments were directly inserted into a T/A cloning vector (pT-Adv) from
AdvanTage PCR Cloning Kit (CLONTECH, no. K 1901-1). A total of 173 independently transformed bacterial colonies were selected at random. Plasmid DNAs isolated from each colony were analysed by PCR using the M13 reverse primer and M13 $(-20)$ primer to identify the size of the inserted cDNA fragments. Ninety-three colonies containing inserted expressed sequence tag (EST) cDNA fragments of different lengths were then sequenced by an automated sequencer. Nucleotide BLAST searches were performed to compare the sequence of these 93 EST cDNA fragments with that of known genes or ESTs presented in the GenBank database.

The full-length cDNA of clone 81 was obtained by designing the $5^{\prime}$ primer (5'-GAGTCTGAGAATGCAAAGTG-3') to match the $5^{\prime}$-end sequence of mouse RGS2 (U67187), and synthesizing the reverse primer (5'-AATTCGCGGCCGCTTTTTTTTTTTTTTT-3') according to the $3^{\prime}$-end sequence of EST-81 cDNA fragment. Subsequently, RT-PCR was performed using mRNA from the day 5 pregnant mouse uterus as the template to obtain the full-length cDNA of clone 81 . The PCR product was subsequently subcloned into PMD18-T for sequencing.

\section{Northern blot analysis}

For northern blot analysis, no attempt was made to separate the embryos from the uteri before day 7 of pregnancy. However, the embryos were separated from the uteri on days 7, 8 and 9 of pregnancy. Total RNA was extracted from uterine and non-uterine tissues as described above. Total RNA from each sample (15 $\mu \mathrm{g}$ per lane) was subjected to electrophoresis through a $1 \%$ $(\mathrm{w} / \mathrm{v})$ agarose gel containing formaldehyde (Sambrook et al., 1989) and then transferred on to a nylon membrane by capillary blotting in $20 \times$ sodium chloride, sodium citrate buffer (SSC) overnight. Meanwhile, $5 \mu \mathrm{g}$ total RNA of the same batch of RNA samples was subjected to electrophoresis on another $1 \%$ agarose gel and stained with ethidium bromide solution (EB) to detect the amount and quality of each RNA sample. The membrane was maintained at $80^{\circ} \mathrm{C}$ for $2 \mathrm{~h}$, followed by UV cross-linking for $3 \mathrm{~min}$. The radiolabelled cDNA probes were generated by random primer labelling of $25 \mathrm{ng}$ CDNA with $\left[\alpha{ }^{32} \mathrm{P}\right]-\mathrm{dCTP}$ (50 uCi per reaction). After the membrane had been pre-hybridized at $42^{\circ} \mathrm{C}$ for $6 \mathrm{~h}$ in the hybridization buffer $(50 \%(\mathrm{v} / \mathrm{v})$ formamide, $2.5 \times$ Denhardt's solution, $0.1 \%(\mathrm{w} / \mathrm{v}) \mathrm{SDS}, 1.0 \mathrm{mmol}$ EDTA I $\mathrm{I}^{-1}, 5 \times \mathrm{SSC}$, $50.0 \mathrm{mmol} \mathrm{Na} \mathrm{PO}_{4} \mathrm{I}^{-1}, 0.1 \mathrm{mg}$ sheared herring sperm DNA ml-1), the pre-hybridization buffer was replaced by the fresh hybridization buffer. The denatured probes were then added into the hybridization buffer and incubated at $42^{\circ} \mathrm{C}$ overnight. After hybridization, the membrane was rinsed twice in $6 \times \mathrm{SSC}$ at room temperature (22$25^{\circ} \mathrm{C}$ ), twice in $2 \times \mathrm{SSC} / 0.1 \%$ SDS for $20 \mathrm{~min}$ each at room temperature, and twice in $0.2 \times \mathrm{SSC} / 0.1 \%$ SDS for 20 min each at $42^{\circ} \mathrm{C}$. Autoradiography was performed using the Kodak BioMax film. The absorbance of the 
hybridization signals was quantified. Loading variation was calibrated by washing the membrane with $1 \mathrm{mmol}$ EDTA $\mathrm{I}^{-1} / 0.1 \%$ SDS at $60^{\circ} \mathrm{C}$ for $3 \mathrm{~h}$ to strip the blots after autoradiography and staining directly with $0.02 \%(\mathrm{w} / \mathrm{v})$ methylene blue dye in 0.3 mol sodium acetate $\mathrm{I}^{-1}$, in addition to the detection of EB-stained $18 \mathrm{~S}$ rRNA bands.

Besides clone 81, another three candidate genes needed to be detected whether or not their expression was upregulated at the implantation sites. Therefore, for each northern blot experiment, four membranes were prepared for four different probes. After developing the films, these membranes were washed and re-used for different probes to confirm the results of northern blot analysis, that is the northern blot analysis experiments were repeated at least once for each probe.

\section{In situ hybridization}

The plasmid containing inserted cDNA was linearized with appropriate enzymes for labelling. Digoxigenin (DIG)-labelled antisense or sense cRNA probes were transcribed in vitro using a DIG RNA labelling kit (T7 for sense and SP6 for antisense; Boehringer Mannheim, Mannheim).

Uteri were cut into 4-6 $\mathrm{mm}$ pieces and flash frozen in liquid nitrogen. Frozen sections $(10 \mu \mathrm{m})$ were mounted on 3-aminopropyltriethoxy-silane-coated (Sigma, St Louis, MO) slides and fixed in $4 \%(\mathrm{w} / \mathrm{v})$ paraformaldehyde solution in PBS. The sections were washed twice in PBS, placed in 1\% (v/v) Triton-X100 for 20 min and washed again in PBS three times. After the prehybridization in the solution of $50 \%$ formamide and $5 \times$ SSC $\left(1 \times\right.$ SSC is 0.15 mol sodium chloride $\mathrm{I}^{-1}, 0.015 \mathrm{~mol}$ sodium citrate $\mathrm{I}^{-1}$ ) at room temperature for $15 \mathrm{~min}$, the sections were hybridized in the hybridization buffer $(5 \times$ SSC, $50 \%$ formamide, $0.02 \%$ BSA, $250 \mu \mathrm{g}$ yeast tRNA $\mathrm{ml}^{-1}, 10 \%(\mathrm{w} / \mathrm{v})$ dextran sulphate, $1 \mu \mathrm{g} \mathrm{ml} \mathrm{m}^{-1}$ denatured DIG-labelled antisense or sense RNA probe for mouse RGS2) at $55^{\circ} \mathrm{C}$ for $16 \mathrm{~h}$. After hybridization, the sections were washed in $50 \%$ formamide $/ 5 \times$ SSC at $55^{\circ} \mathrm{C}$ for $15 \mathrm{~min}, 50 \%$ formamide $/ 2 \times \mathrm{SSC}$ at $55^{\circ} \mathrm{C}$ for $30 \mathrm{~min}, 50 \%$ formamide/ $0.2 \times \mathrm{SSC}$ at $55^{\circ} \mathrm{C}$ twice for $30 \mathrm{~min}$ each, and $0.2 \times$ SSC at room temperature for $5 \mathrm{~min}$. After non-specific binding was blocked in $1 \%$ block mix (Boehringer Mannheim) for $1 \mathrm{~h}$, the sections were incubated in sheep anti-DIG antibody conjugated with alkaline phosphatase $1: 5000$, Boehringer Mannheim) in $1 \%$ block mix overnight at $4^{\circ} \mathrm{C}$. The signal was visualized with $0.4 \mathrm{mmol} 5$-bromo-4-chloro3 -indolyl phosphate $\mathrm{I}^{-1}$ and $0.4 \mathrm{mmol}$ nitroblue tetrazolium $\mathrm{I}^{-1}$ in the buffer containing $100 \mathrm{mmol}$ Tris$\mathrm{HCl} \mathrm{I}^{-1}, \mathrm{pH} 9.5,100 \mathrm{mmol} \mathrm{NaCl} \mathrm{I}^{-1}$ and $50 \mathrm{mmol}$ $\mathrm{MgCl}_{2} \mathrm{I}^{-1}$. Endogenous alkaline phosphatase activity was inhibited with $2 \mathrm{mmol}$ levamisole $\mathrm{I}^{-1}$ (Sigma). All of the sections were counterstained with $1 \%(\mathrm{w} / \mathrm{v})$ methyl green in 0.12 mol glacial acetic acid $\mathrm{I}^{-1}$ and 0.08 mol sodium acetate $\mathrm{I}^{-1}$ for $30 \mathrm{~min}$. (a)

(b)
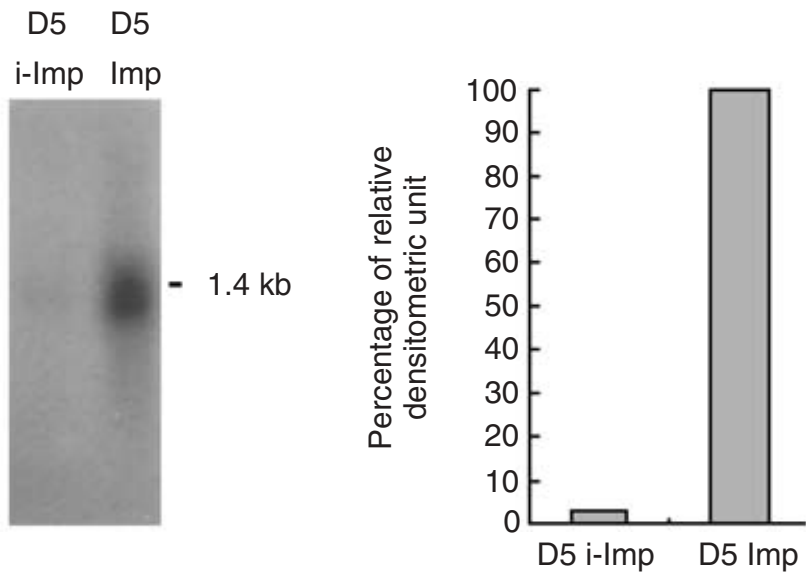

Fig. 1. (a) Northern blot analysis of mRNA detected by using the 273 bp EST-81 cDNA fragment as a probe. Total RNA (15 $\mu \mathrm{g})$ was extracted from implantation sites ( $(\mathrm{mp})$ and inter-implantation sites (i-Imp) of mice on day 5 (D5) of pregnancy. (b) The relative expression of mRNA in implantation sites compared with interimplantation sites on D5 of pregnancy. The mRNA in the interimplantation sites was expressed as a percentage of that in the implantation sites (100\%).

\section{Results}

Subtractive hybridization and confirmation of clone 81 by northern blot analysis

The cDNA fragments that were in high abundance at the implantation sites on day 5 of pregnancy were collected using subtractive hybridization technique to identify genes which are upregulated at implantation sites during implantation. Subtracted cDNA products were subcloned into pT-Adv vector. In total, 173 colonies were detected by PCR, of which 93 colonies were confirmed to contain the subtracted cDNA in different lengths from $150 \mathrm{bp}$ to $1.2 \mathrm{~kb}$. The nucleotide sequences of these 93 colonies were determined. Seventy-one EST sequences, which were independent among the 93 colonies, were compared with the GenBank database. The inserted cDNA sequence of clone 81 (EST-81, $273 \mathrm{bp}$ ) showed $92 \%$ identity in 200 nucleotides to rat RGS2 (accession no. AF279918) and 100\% identity in 92 nucleotides to mouse RGS2 (accession no. U67187). The EST-81 cDNA fragment was amplified and used as a probe to determine the mRNA expression pattern in the non-pregnant uterus, and the uteri at implantation and inter-implantation sites on day 5 of pregnancy by northern blot analysis (Fig. 1a). A signal band of about $1.4 \mathrm{~kb}$ was detected in the RNA samples from the uterus at day 5 of pregnancy. Equal loading of RNA samples was confirmed by EB-stained $18 \mathrm{~S}$ rRNA bands and direct methylene blue staining of the membrane. The mRNA detected by EST-81 probe was expressed in the uterus on day 5 of pregnancy. This gene was mainly located at implantation sites. On the basis of 


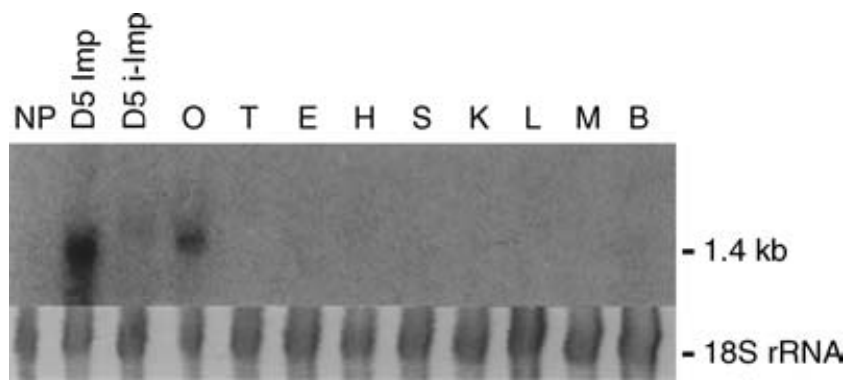

Fig. 2. Northern blot analysis of the tissue specificity of the gene presented by the EST-81 sequence. RNA was isolated from uterus $(\mathrm{NP})$, ovary $(\mathrm{O})$, heart $(\mathrm{H})$, spleen $(\mathrm{S})$, kidney $(\mathrm{K})$, liver $(\mathrm{L})$, muscle $(\mathrm{M})$ and brain (B) of an adult female mouse, and from testis (T) and epididymis (E) of an adult male mouse. The relative expression of this gene in the above tissues was compared with that at implantation sites (Imp) and inter-implantation sites (i-Imp) of mice at day 5 (D5) of pregnancy. Total RNA (15 $\mu \mathrm{g})$ was loaded into each lane. The top panel shows the $1.4 \mathrm{~kb}$ signal detected by EST-81 sequence, and the lower panel shows the 18S rRNA bands of each RNA sample.

densitometric analysis using the GIS3.60 Image Analyze System (Tanon Company, Shanghai), the expression at the inter-implantation sites was about $6 \%$ of that at implantation sites (Fig. 1b).

\section{Cloning the full cDNA sequence of clone 81}

The sequence of EST-81 cDNA fragment had a high similarity to the mouse RGS2 cDNA (accession no. U67187) but had a longer $3^{\prime}$ sequence containing the polyA ${ }^{+}$tail. RT-PCR of mouse uterine mRNA was performed using a forward primer based on the $5^{\prime}$-end sequence of $U 67187$ and a reverse primer based on the 3 '-end sequence of EST-81 cDNA fragment, to determine whether the sequence that is unique to EST-81 is authentic to U67187. A 1364 bp PCR product was obtained, and then subcloned into pMD18-T vector and sequenced. The sequence of this $1364 \mathrm{bp}$ cDNA contained all of the $1240 \mathrm{bp}$ sequence of U67187 and its entire 3 '-end sequence (124 bp) was unique to EST-81 and contained the poly $(\mathrm{A})$ tail. These results indicate that this $1364 \mathrm{bp}$ sequence represented the full-length cDNA of mouse RGS2, and the sequence unique to EST-81 was part of the authentic 3'-end of RGS2 gene. Therefore, this sequence was subsequently deposited in GenBank (accession no. AF432916). Among the 1240 bp homologous sequence, in total six nucleotides differed between AF432916 and U67187; four of these nucleotides (127G, 128-G, 244-G and 245-C) were in the encoding region. The amino acid sequences predicted from AF432916 and U67187, consisting of 211 amino acids, were the same except for four amino acids (39-Lys, 40Asp, 78-Gln and 79-Leu). Another 1354 bp full-length cDNA sequence of mouse RGS2 became available in
GenBank (Accession no. BC023001). The amino acid sequence of AF432916 was $100 \%$ identical to that of BC023001.

The small scale preparation of plasmid pMD18T/RGS2 was performed to amplify the RGS2 cDNA. This 1364 bp cDNA molecule was digested by Banll and Hincll (recognition sequences were located at the 629634 bp and 1108-1113 bp of AF432916, respectively), and two fragments (633 bp and 477 bp in length, respectively) were obtained. These two fragments, which were not present in EST-81 sequence, were tested by northern blot analysis as the probe, respectively. The expression patterns identical to the previous hybridization signal by using EST-81 as the probe were obtained (data not shown). This confirmed that AF432916 is the fulllength cDNA of clone 81, which was upregulated at implantation sites of mouse uterus.

\section{Tissue distribution of RGS2 mRNA}

Northern blot analysis was performed to investigate the expression of RGS2 gene in other non-uterine tissues. In the present study, the ovary was collected from oestrous female mice, and the testis and epididymis from the adult male mice. All of the other tissues, including heart, spleen, kidney, liver, muscle and brain, were collected from day 5 pregnant mice. The high mRNA expression was detected only in the uterus and ovary (Fig. 2).

Northern blot analysis of RGS2 expression in the uterus during early pregnancy

The expression pattern of mouse RGS2 in the uterus during early pregnancy was determined by analysing total RNA samples from the uteri of oestrous and pregnant mice by northern blot analysis using the 273-bp EST81 cDNA fragment as the probe. RGS2 expression was detected both in the uterus and embryo. In the implantation sites, positive signals were detectable from day 5 of pregnancy (Fig. 3a), increased from day 6 to day 8 of pregnancy, and decreased on day 9 (Fig. 3b). However, for the inter-implantation sites, positive signals were observed only after day 7 of pregnancy, but the expression of RGS2 mRNA reached its peak on day 7 , and significantly decreased from day 8 to day 9 of pregnancy. In addition, the expression of RGS2 mRNA at the implantation sites was much higher than that in the inter-implantation sites on days $5-8$ of pregnancy.

In situ hybridization of RGS2 mRNA in the uterus during early pregnancy

The expression of RGS2 gene in the uterus was determined by in situ hybridization using DIG-labelled RGS2. No positive signal was detected in the uterus 
(a)

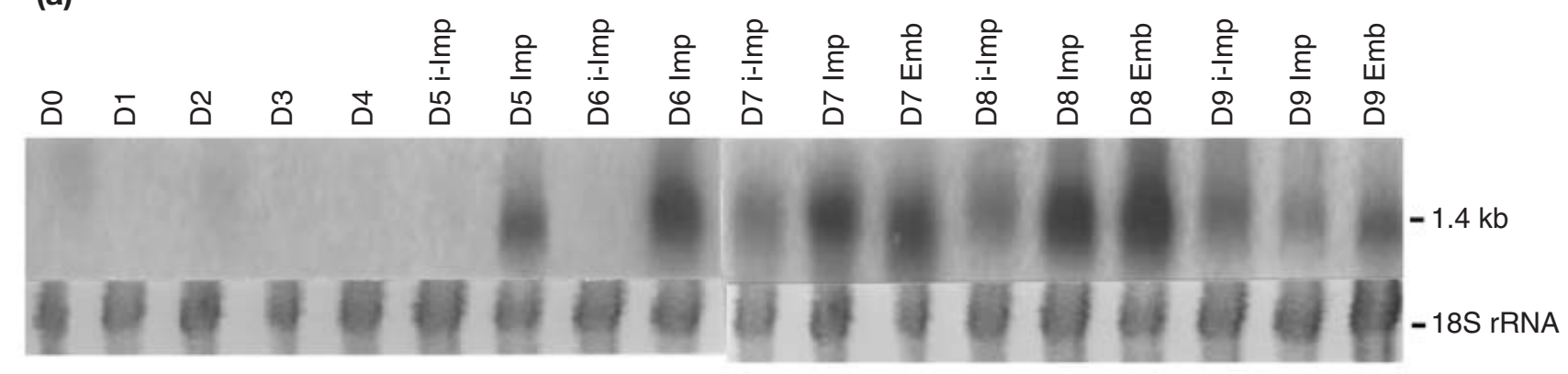

(b)

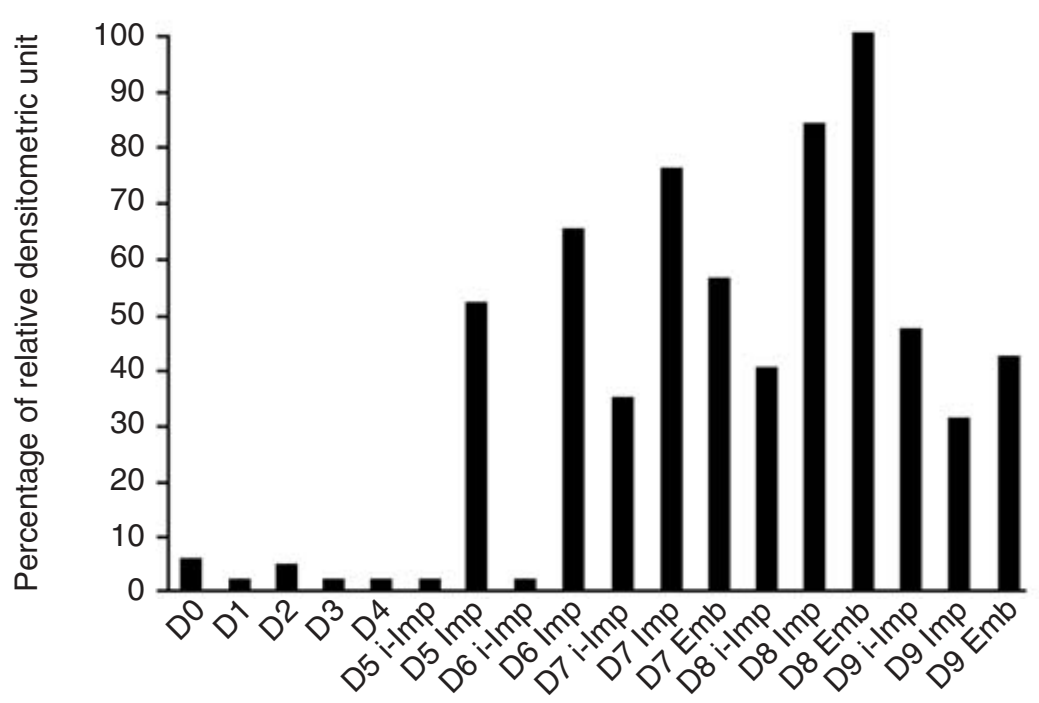

Fig. 3. (a) Northern blot analysis of mRNA detected by using the 273 bp EST-81 cDNA fragment as probe. Total RNA (15 $\mu$ g) was extracted from uteri of non-pregnant mice at oestrus (day 0 ) and day 1 to day 4 pregnant mice (D1-D4, and from inter-implantation sites (i-Imp) and implantation sites (Imp) on day 5 and day 9 (D5-D9). On day 7, 8 and day 9, embryos (Emb) were also separated from the implantation sites. The top panel shows the $1.4 \mathrm{~kb}$ signal detected by the EST-81 fragment cDNA, and the lower panel shows the $18 \mathrm{~S}$ rRNA bands of each RNA sample. (b) The relative expression of mRNA in the uterine tissues throughout the peri-implantation period (days 1-9). mRNA was expressed as a percentage of that in the day 8 embryonic tissues (100\%).

from day 1 (Fig. 4a) to day 3 of pregnancy. On day 4, the signal was observed in the sub-luminal stromal cells (Fig. 4b). From day 5 to day 8 of pregnancy, RGS2 signal was localized mainly in the primary decidualized region at the implantation site (Fig. 4c,e,f,h). Consistent with the results of northern blot analysis, no strong positive signal was seen in the inter-implanation site on day 5 (Fig. 4d) and day 8 (Fig. 4i). No signal was seen in the day 4 pseudopregnant uteri (Fig. 4k). RGS2 was also highly expressed in the decidualized cells under artificial decidualization (Fig. 4I). However, no distinctively positive signal was detected in the uteri of ovariectomized mice when these mice were treated with oestradiol or progesterone (data not shown). There was no detectable signal in the uterus under delayed implantation (Fig. $4 \mathrm{~m}$ ). After delayed implantation was terminated by oestrogen treatment, the expression of RGS2 mRNA did not in- crease significantly, although some weak signals were observed in the subluminal stroma at implantation site (Fig. 4n).

\section{Discussion}

In the present study, subtractive hybridization was used to search for genes that are upregulated in the mouse uterus at the implantation sites on day 5 of pregnancy. By using northern blot analysis, it was possible to detect several cDNA EST fragments exhibiting different expression between the implantation and inter-implantation sites, one of which was identified as mouse RGS2. The full cDNA sequence of mouse RGS2 was then determined indicating that the sequence is longer than the previously published sequence of mouse RGS2 (U67187), and that there are some differences in the open reading frame. 

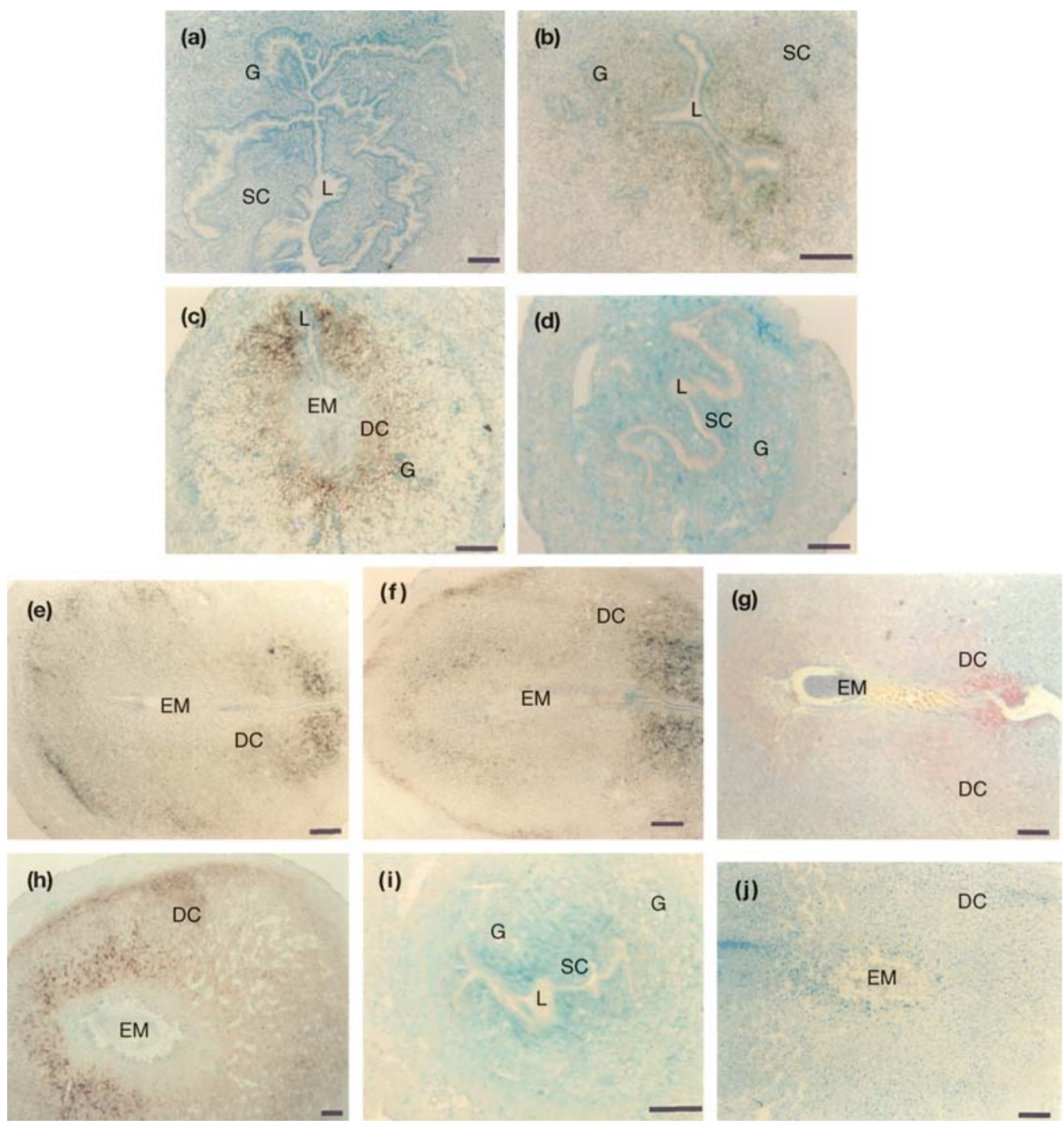

Fig. 4. For legend see facing page.

However, the sequence is exactly the same as the recently published sequence of mouse RGS2 (BC023001).

In the present study, uterine RGS2 mRNA markedly increased at the embryo implantation sites after day 5 of pregnancy. RGS2 expression was observed in endometrial stromal cells throughout the peri-implantation period (days 5-9). The increase of RGS2 expression was also observed in the artificially induced decidualized cells, indicating that this increase did not require the presence of an embryo in the uterus. In the mouse, the establishment of a receptive uterus to support implantation is regulated by co-ordinated effects of progesterone and oestrogen (Huet-Hudson et al., 1989). However, it is evident from the present study that the administration of progesterone and oestrogen did not significantly affect the expression of RGS2 in the mouse uterus.

The precise function of RGS2 in embryo implantation remains to be established. As RGS2 can selectively bind Gq $\alpha$ (Heximer et al., 1997, 2001), one function of RGS2 might be to attenuate phospholipase C (PLC) 

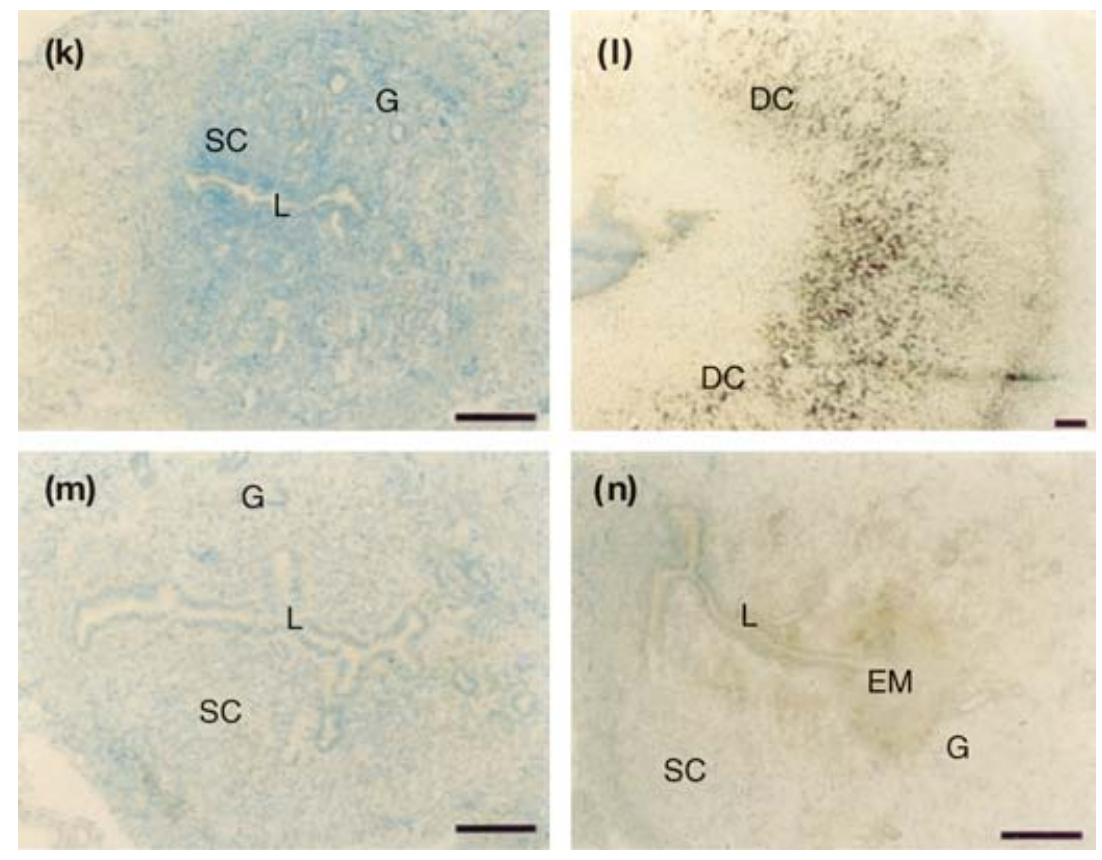

Fig. 4. In situ hybridization of the regulator of $\mathrm{G}$ protein signalling protein 2 (RGS2) mRNA in the mouse uterus on (a) day 1 and (b) day 4 of pregnancy; at the implantation site of (c) day 5, (e) day 6, (f) day 7 and (h) day 8; at the inter-implantation site of (d) day 5 and (i) day 8 ; in the uterus of (k) day 4 pseudopregnant mouse and (I) artificially induced decidualization of pseudopregnant mouse; and $(m, n)$ delayed implantation before and after activation using digoxigenin-labelled probes generated against RGS2 cDNA. (j) is the same as (h), but sense probe was used as control. (g) is the interleukin 11 receptor staining at the implantation site of day 7 pregnant mouse to identify the decidual cells. DC: decidual cells; EM: embryo; G: gland; L: lumen of uterus; SC: stromal cells. Scale bars represent $50 \mu \mathrm{m}$.

medicated signalling of second messengers such as inositol triphosphate and $\mathrm{Ca}^{2+}$ (Hepler, 1999; GrafasteinDunn et al., 2001). In addition, as PLC activation has also been associated with $\mathrm{K}^{+}$conductance, it has been suggested that RGS proteins increase the deactivation of inward-rectifying $\mathrm{K}^{+}$channels (DeVries and Farquahar, 1999). Furthermore, it was reported that RGS2 attenuates the activation of AC-III and cAMP-gated $\mathrm{Ca}^{2+}$ channels (Sinnarajah et al., 2001; Kerhl and Sinnarajah, 2002). The correlation of RGS2 with ion gating and membrane conductance indicates a potentially important role of RGS2 in embryo implantation, as intracellular calcium flux is an important determinant of gene expression (Hardingham et al., 1997). It is also evident from previous reports that RGS2 protein could stimulate the proliferation of T cells and production of IL-2 (OliveiraDos-Santos et al., 2000), and the activation of B lymphocytes could increase the RGS2 mRNA in vivo (Reif and Cyster, 2000). As IL-2 can strongly inhibit monoclonal nonspecific suppressor factor $\beta$ (MNSF $\beta$ ) activity (Nie et al., 2000), the upregulation of RGS2 expression at the implantation sites would attenuate the bio-activity of MNSF $\beta$ at the same sites. This finding supports the finding of Nie et al. (2000) that the expression of MNSF $\beta$, a molecule that may participate in the uterine immune tolerance during pregnancy, was downregulated at implantation sites in mice. Therefore, another potential function of RGS2 in implantation and early pregnancy might be to participate in the local immunoregulation of uterine tissues during implantation.

The array of RGS proteins reportedly attenuate signal transduction initiated by a variety of mitogens and morphogens, including hormones that bind to G-proteincoupled receptors, to stimulate cell proliferation and differentiation (DeVries and Farquahar, 1999; Guan and Hun, 1999; Hepler, 1999; Siderovski et al., 1999). However, during the mouse embryo implantation process, the attachment reaction is followed by adherence and penetration by trophoblast cells through the underlying basement membrane and results in proliferation and differentiation of stromal cells into decidual cells. Therefore, it is not surprising that RGS2 expression is acutely upregulated in mouse uterine tissues during the process of implantation and decidualization.

In summary, mouse RGS2 was cloned by using subtracted hybridization to identify differentially expressed 
genes between implantation and inter-implantation sites on day 5 of pregnancy in the mouse. RGS2 expression was upregulated at implantation sites. The upregulated expression of RGS2 mRNA in the mouse uterus during the early pregnancy indicates that it may play a crucial role in the process of embryo implantation.

This research was supported by the grant of National Basic Research Programme (No. TG1999055903) from the Ministry of Science and Technology, P. R. China.

\section{References}

Carson DD, Bagchi I, Dey SK, Enders AC, Fazleabas AT, Lessey BA and Yoshinaga K (2000) Embryo implantation Developmental Biology 223 217-237

DeVries L and Farquahar MG (1999) RGS proteins: more than just GAPs for heterotrimeric G proteins Trends in Cell Biology 9 138-144

Diatchenko L, Chenchik A and Siebert P (1998) Suppression subtractive hybridization: a method for generating subtracted CDNA libraries starting from poly $(\mathrm{A}+)$ or total RNA RT-PCR. In Methods for Gene Clone and Analysis pp 213-239 Eds P Siebert and J Larrick. BioTechniques Books MA

Grafastein-Dunn E, Young KH, Cockett MI and Khawaja XZ (2001) Regional distribution of regulators of G-protein signaling (RGS) 1, 2, 13, 14, 16, and GAIP messenger ribonucleic acids by in situ hybridization in rat brain Brain Research Molecular Brain Research 88 113-123

Guan KL and Han M (1999) A G-protein signaling network mediated by an RGS protein Gene Development 13 1763-1767

Hardingham GE, Chawla S, Johanson CM and Bading H (1997) Distinct functions of nuclear and cytoplasmic calcium in the control of gene expression Nature 385 260-265

Hepler JR (1999) Emerging roles for RGS proteins in cell signaling Trends in Pharmacologcial Science 20 376-382

Heximer SP, Watson N, Linder ME, Blumer KJ and Hepler JR (1997) RGS2/G0S8 is a selective inhibitor of Gq $\alpha$ function Proceedings National Academy of Science USA 9414 389-14 393

Heximer SP, Lim H, Bernard JL and Blumer KJ (2001) Mechanisms governing subcellular localization and function of human RGS2 Journal of Biological Chemistry 27614 195-14 203

Huet-Hudson YM, Andrews GK and Dey SK (1989) Cell type-specific localization of c-Myc protein in the mouse uterus: modulation by steriod hormones and analysis of the peri-implantation period Endocrinology 125 1683-1690
Kehrl JH and Sinnarajah S (2002) RGS2: a multifunctional regulator of G-protein signaling International Journal of Biochemical Cell Biology 34 432-438

Nie GY, Butt AR, Salamonsen L and Findlay J (1997) Hormonal and non-hormonal agents ate implantation as targets for contraception Reproduction, Fertility and Development 9 65-76

Nie GY, Li Y, Hampton AL, Salamonsen LA, Clements JA and Findlay JK (2000) Identification of monoclonal nonspecific suppressor factor beta (MNSF $\beta$ ) as one of the genes differentially expressed at implantation sites compared to interimplantation sites in the mouse uterus Molecular Reproduction and Development 55 351-363

Oliveira-Dos-Santos AJ, Matsumoto G, Snow BE et al. (2000) Regulation of T-cell activation, anxiety and make aggression by RGS2 Proceedings National Academy of Science USA 9712 272-12 277

Paria BC, Huet-Hudson YM and Dey SK (1993) Blastocyst's state of activity determines the 'window' of implantation in the mouse receptive uterus Proceedings National Academy of Science USA 9010159 10162

Psychoyos A (1973) Endocrine control of egg implantation. In Handbook of Physiology pp 187-215 Eds RO Greep, EG Astwood and SR Geiger. Washington DC, American Physiological Society

Reese J, Das SK, Paria BC and Dey SK (2001) Global gene expression analysis to identify molecular markers of uterine receptivity and embryo implantation Journal of Biological Chemistry 27644 137-44 145

Reif K and Cyster JG (2000) RGS molecule expression in murine B lymphocytes and ability to downregulate chemotaxis to lymphoid chemokines Journal of Immunology 164 4720-4729

Rinkenberger JL, Cross JC and Werb Z (1997) Molecular genetics of implantation in the mouse Developmental Genetics 21 6-20

Sambrook J, Fritsch EF and Maniatis T (1989) Molecular Cloning: a Laboratory Manual Cold Spring Harbor NY, Cold Spring Harbor Laboratory Press

Siderovski DP, Stockbine B and Behe CI (1999) Whither goest the RGS proteins? Critical Reviews of Biochemical Molecular Biology 34215 251

Sinnarajah S, Dessauer CW, Strikumar D, Chen J, Yuen J, Yilma S, Dennis JC, Morrison EE, Vodyanoy V and Kehrl JH (2001) RGS2 regulates signal transduction in olfactory neurons by attenuating activation of adenylyl cyclase III Nature 409 1051-1055

Received 1 October 2002.

First decision 20 November 2002

Revised manuscript received 22 April 2003.

Accepted 1 May 2003. 